conversion reaction manifested as an inability to stand or walk are reported from the Department of Pediatrics, Mayo Clinic, Rochester, MN. There were 9 males and 18 females, ages 8 to 16 years, and duration of the symptoms varied from 1 to 60 weeks. Precipitating events in 17 patients included minor illnesses, school and home related problems, and minor injuries. Onset of symptoms showed seasonal variation with maximal frequency in the winter months and none in the summer and at time of school vacation. The duration of symptoms, estimated at the time of follow-up some 5 to 22 years later, was from a few days to a maximum of 2.5 years. Twenty-two ( $80 \%$ ) said they were healthy and the remainder had minor complaints. None had organic illnesses that might have explained the ataxia. Three had continued mental problems and one was in jail for having killed his parents. (Stickler GB, Cheung-Patton A. Astasia-abasia. A conversion reaction. Prognosis. Clin Pediat Jan 1989;28:12-16).

COMMENT. A prompt and firm diagnosis on the basis of positive in addition to exclusion criteria is advocated, and a neurologic examination and appropriate laboratory tests are essential as a reassurance for both patient and treating physician. Dystonia musculorum deformans can be a pitfall, a disorder frequently misdiagnosed as a conversion reaction initially. In a study of 7 children with neurological symptoms diagnosed as hysterical conversion reactions and reported from Duke University Medical Center (Bangash IH et al AJDC Nov 1988;142:1203) all but one had been misdiagnosed as having organic diseases. When the correct diagnosis was made, all recovered and none relapsed after 3 to 11 months follow-up.

\title{
CHIARI TYPE I MALFORMATION
}

A 13-year-old girl with post-traumatic cerebellar ataxia, transient upper extremity weakness, and lower cranial nerve dysfunction was found to have a Type I Chiari malformation on MRI at the Depts of Neurosurgery and Neurology, San Francisco General Hospital, California. She lost consciousness and had a cardiopulmonary arrest after hitting her neck and head on the windshield in an automobile accident. On the 2nd day, her right upper limb was paralyzed; on day 4 she had upbeating nystagmus and was unable to swallow, phonate, or protrude her tongue; and on day 12 right vocal cord paralysis was noted which recovered by day 15. She continued to have improvement of the lower cranial nerve weakness but the ataxia persisted at the time of discharge. It was thought that the initial cardiopulmonary arrest after trauma and the brain stem dysfunction and ataxia were causally related to the Type I Chiari malformation. The continued improvement argued against surgical decompression. (Mampalam TJ et al. Presentation of Type I Chiari malformation after head trauma. Neurosurgery $1988 ; \underline{23}: 760-762$ ).

COMMENT. This sudden manifestation of symptoms and signs of Chiari I malformation after head and neck trauma is unusual. Previously reported cases include a 3-yearold child who died 48 hours after a mild head injury, a 
$21 / 2$ year-old boy who developed acute paraparesis after a fall, a 17-year-old girl who developed hemianesthesia, nystagmus, dysarthria, and tongue deviation 1 week after chiropractic manipulations, and acquired torticollis after endotracheal anesthesia for tonsillectomy. All cases were found to have Chiari I malformation; only one had an associated syringomyelia. The diagnosis of Chiari I malformation hăs been facilitated by the use of MRI and asymptomatic cases are being uncovered by this imaging technique.

\section{ATAXIA-OCULOMOTOR APRAXIA SYNDROME}

A new spinocerebellar degenerative syndrome has been described in 14 patients from 10 families and reported from the Hopital des Enfants Malades, Paris, France; Montreal Neurological Institute, Canada; Rashid Hospital, Dubai, UAE; Tokyo Women's Medical College, Japan; and University of Colorado Medical School, Boulder, CO. Six of the cases had been reported previously in the Japanese literature and in abstracts. The clinical features included onset between 2 and 7 years of age, ataxia, ocular motor apraxia, choreoathetosis, depressed or absent deep tendon reflexes, dysarthria, masklike facies, intention tremor, and mildly subnormal intellectual function in one half the patients. СT was normal in 6 and showed mild vermal atrophy in 1 . None had conjunctival telangiectasia or abnormal immunoglobulins and a diagnosis of ataxia telangiectasia was considered unlikely. The syndrome was probably genetically determined with an autosomal mode of inheritance; it involved both sexes with consanguinity in 6 of 10 sibships. (Aicardi J, Barbosa C, Andermann E and F, Morcos R, Ghanem Q, Fukuyama Y, Awaya Y, Moe P. Ataxia - ocular motor apraxia; a syndrome mimicking ataxia - telangiectasia. Ann Neurol Oct $1988 ; \underline{24}: 497-502)$.

COMMENT. The differential diagnosis includes Cogan's ocular motor apraxia and ataxia telangiectasia. The authors, of whom 4 are already distinguished by eponymous syndromes (Aicardi $\mathrm{J}$, Andermann $\mathrm{E}$ and $\mathrm{F}$, and Fukuyama $\mathrm{Y}$ ), report a specific neurodegenerative syndrome of genetic origin with patients originating from widely separate geographical areas and from different ethnic backgrounds. Ataxia, areflexia, and ocular muscle paralyses are also featured in the Fisher syndrome.

\section{SEIZURES AND DIET}

\section{OLIGOANTIGENIC DIET FOR EPILEPSY AND MIGRAINE}

A diet low in antigenic items was used to treat 63 children with epilepsy refractory to medication at the Depts of Neurology, Immunology, and Dietetics, The Hospital for Sick Children, Great Ormond Street, and the Institute of Child Health, London, England. The authors had previously reported beneficial effects of the "oligoantigenic" diet in the treatment of migraine (Lancet $1983 ; \underline{2}: 865$ ) and the hyperkinetic syndrome (Lancet 1985; 1:940). The diet consisted of 2 meats (lamb and 